\title{
Anticoagulation therapy and the risk of perioperative brain injury in neonates with congenital heart disease
}

Lara M. Leijser, MD, PhD, ${ }^{\mathrm{a}, \mathrm{b}}$ Vann Chau, MD, ${ }^{\mathrm{a}}$ Mike Seed, MD, ${ }^{\mathrm{c}}$ Kenneth J. Poskitt, MDCM, ${ }^{\mathrm{d}, \mathrm{e}, \mathrm{f}}$ Anne Synnes, MDCM, ${ }^{\mathrm{e}, \mathrm{f}}$ Susan Blaser, MD, ${ }^{\mathrm{g}}$ Stephanie H. Au-Young, PhD, ${ }^{\mathrm{a}}$ Edward J. Hickey, MD, Andrew Campbell, MD, ${ }^{i}$ Patrick S. McQuillen, MD, ${ }^{j}$ and Steven P. Miller, MDCM ${ }^{\mathrm{a}, \mathrm{f}}$

\section{ABSTRACT}

Objective: There is considerable variability in anticoagulation use in neonates with transposition of the great arteries (TGA) and single ventricle physiology (SVP) for secondary stroke prevention and primary cardiovascular indications. Leveraging cross-center differences in anticoagulation use, we compared the risk of new postoperative brain injury in neonates with TGA and SVP treated with anticoagulation relative to untreated neonates.

Methods: Two-center observational cohort study of 118 term-born neonates with TGA $(\mathrm{n}=83)$ and SVP $(\mathrm{n}=35)$, undergoing cardiopulmonary bypass surgery and pre- and postoperative brain magnetic resonance imaging. Anticoagulation and antiplatelet therapy details were obtained. Magnetic resonance images were scored for stroke, white matter injury, and hemorrhage. New postoperative injury was compared between neonates with and without anticoagulation for the 2-center cohort, and subsequently stratified by cardiac lesion type and anticoagulation indication.

Results: Thirty-six out of 118 neonates (29\%) received anticoagulation: 11 $(30 \%)$ for preoperative stroke, $20(56 \%)$ for preoperative peripheral/intracardiac thrombus, and $5(14 \%)$ for Blalock-Taussig shunt. Five out of 36 neonates $(14 \%)$ treated with anticoagulation also received antiplatelet therapy. Although no differences were identified for the 2-center cohort or for neonates with TGA separately, significantly more new postoperative parenchymal brain injury $(P=.04)$, particularly stroke, was found in SVP neonates with compared to without anticoagulation $(31 \%$ vs $5 \%)$. In neonates who experienced preoperative stroke, new subdural hemorrhage (36\% vs $0 \%$ ) was more frequent in neonates treated with anticoagulation therapy compared with those without anticoagulation therapy.

Conclusions: In our cohort of neonates with TGA and SVP, anticoagulation for preoperative stroke, preoperative thrombus, and/or Blalock-Taussig shunt did not have the anticipated benefit of preventing new perioperative brain injury. These findings indicate the critical need for rigorous randomized trials on the safety and effectiveness of anticoagulation therapy in this population. ( $\mathrm{J}$ Thorac Cardiovasc Surg 2019;157:2406-13)

From the Divisions of ${ }^{\mathrm{a}}$ Neurology and ${ }^{\mathrm{c}}$ Cardiology, Department of Pediatrics, ${ }^{\mathrm{g}} \mathrm{De}-$ partment of Diagnostic Imaging, and ${ }^{\mathrm{h}}$ Division of Cardiovascular Surgery, Department of Surgery, The Hospital for Sick Children and The University of Toronto, Toronto, Ontario, Canada; 'bivision of Neonatology, Department of Pediatrics, University of Calgary and Alberta Children's Hospital Research Institute, Calgary, Alberta, Canada; Departments of ${ }^{\mathrm{d}}$ Radiology, ${ }^{\mathrm{e}}$ Pediatrics, and ${ }^{\mathrm{i}}$ Pediatric Cardiovascular and Thoracic Surgery, British Columbia Children's and Women's Hospitals and University of British Columbia, Vancouver, British Columbia, Canada; ${ }^{f}$ British Columbia Children's Hospital Research Institute, Vancouver, British Columbia, Canada; and ${ }^{\mathrm{j}}$ Departments of Pediatrics and Neurology, University of California, Benioff Children's Hospital, San Francisco, California, United States. Supported by the Canadian Institutes of Health Research (CIHR; MOP93780 and MOP142204), and a Research Fellowship Competition Award from The Research

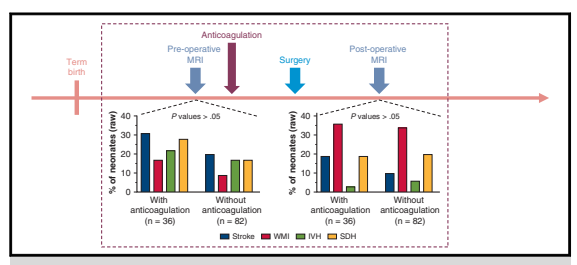

Rates of new postoperative brain injury are not different in neonates with congenital heart disease treated with/without anticoagulation.

\section{Central Message}

Rigorous randomized studies are needed to determine the safety and effectiveness of perioperative anticoagulation therapy for further brain injury protection in neonates with complex CHD.

\section{Perspective}

Anticoagulation may prevent perioperative brain injury in neonates with CHD with preoperative stroke or thromboembolic risk. Approaches to anticoagulation differ considerably across centers. In neonates with CHD, anticoagulation did not have the anticipated benefit of preventing further perioperative brain injury, supporting the need for randomized studies on the safety and efficacy of anticoagulation.

See Commentary on page 2414 .
Training Centre, The Centre of Brain and Mental Health, and The Labatt Family Heart Centre, at The Hospital for Sick Children, Toronto, Canada to Dr Leijser. The funding sources had no involvement in the study design, in the collection, analysis, and interpretation of data, in writing the manuscript, or in the decision to submit the manuscript for publication.

Received for publication Jan 10, 2018; revisions received Dec 20, 2018; accepted for publication Feb 6, 2019; available ahead of print April 10, 2019.

Address for reprints: Steven P. Miller, MDCM, Division of Neurology, Department of Pediatrics, The Hospital for Sick Children, 555 University Ave, Rm 6546, Toronto, Ontario M5G 1X8 Canada (E-mail: steven.miller@sickkids.ca). $0022-5223 / \$ 36.00$

Copyright (C) 2019 by The American Association for Thoracic Surgery https://doi.org/10.1016/j.jtcvs.2019.02.029 


\section{Abbreviations and Acronyms \\ ASA = acetylsalicylic acid \\ $\mathrm{BCCH}=$ The British Columbia Children's Hospital \\ HSC $=$ The Hospital for Sick Children \\ LMWH $=$ low-molecular-weight heparin \\ MRI = magnetic resonance imaging \\ SVP = single ventricle physiology \\ TGA $=$ transposition of the great arteries}

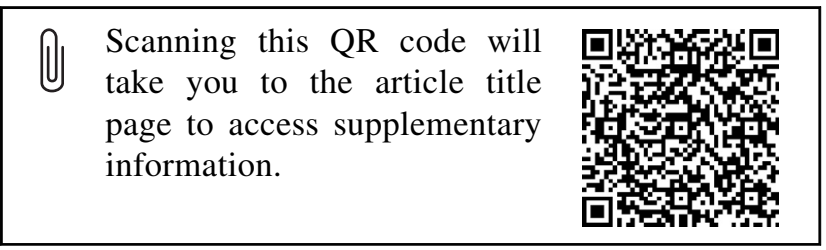

Brain injury is a common and clinically significant complication in neonates with congenital heart disease requiring cardiopulmonary bypass surgery early in life. Recent studies using magnetic resonance imaging (MRI) before and after cardiac surgery suggest that up to two thirds of neonates acquire brain injury in the postoperative period. ${ }^{1-12}$

Transposition of the great arteries (TGA) and single ventricle physiology (SVP) are 2 common forms of complex congenital heart disease. Ischemic strokes affect up to $25 \%$ of neonates with these lesions. ${ }^{1,7,13,14}$ Stroke recurrence is also high in this population, with up to $27 \%$ of neonates experiencing recurrent stroke, particularly during the perioperative period. ${ }^{7,15}$ The etiology of stroke in neonates with complex congenital heart disease is multifactorial, related to abnormal cardiac anatomy and function leading to thromboemboli, as well as complications and interventions promoting a prothrombotic state. Given this, and the concern for a high recurrence risk, anticoagulation is used routinely in some centers when an ischemic stroke is identified in neonates with complex congenital heart disease. Yet, in other centers, anticoagulation is rarely used for secondary stroke prevention in this population.

Anticoagulation is also used in neonates with complex congenital heart disease for primary cardiovascular indications, such as a peripheral or intracardiac thrombus or Blalock-Taussig shunt, to prevent postoperative thromboemboli formation or extension and subsequent brain injury. In the setting of a Blalock-Taussig shunt, antiplatelet therapy (ie, acetylsalicylic acid [ASA]) is also frequently used as prophylaxis.

The considerable center-based differences in anticoagulation use in neonates with complex congenital heart disease is related to a lack of robust evidence that anticoagulation for these indications prevents perioperative brain injury. Practice variability provides a key opportunity to examine the relationship between anticoagulation therapy and new postoperative brain injury, and to inform future clinical trials on optimal anticoagulation therapy.

For this observational cohort study, to have wide variability in anticoagulation exposure, we identified 2 cardiac centers with a relatively high and low rate in anticoagulation use. Our primary objective was to compare the risk of new postoperative brain injury in neonates with TGA and SVP treated with anticoagulation relative to neonates who were not treated. Additionally, we determined whether the association of anticoagulation with new postoperative brain injury was modified by cardiac lesions type (TGA or SVP) and by indication for anticoagulation (preoperative ischemic stroke, preoperative thrombus, or Blalock-Taussig shunt prophylaxis). We then examined the incidence of new postoperative brain injury in neonates with additional antiplatelet therapy. We hypothesized that anticoagulation therapy started for preoperative stroke or cardiovascular indications would be associated with a lower risk of new postoperative embolic brain injury in neonates with SVP given the right-to-left shunt, risk of complications, and need for interventions that persist postoperatively.

\section{METHODS \\ Patients}

Term-born neonates (>36 weeks' postmenstrual age) with TGA and SVP, born between September 2001 and December 2016, undergoing cardiopulmonary bypass surgery within 3 months of life, and enrolled in a prospective cohort study, including pre- and postoperative brain MRI, were studied for this secondary analysis. The primary prospective cohort study did not involve a trial to test drugs or a novel procedure. Neonates were admitted to the cardiac unit of The Hospital for Sick Children (HSC) or The British Columbia Children's Hospital $(\mathrm{BCCH})$, both regional, tertiary-level cardiac referral centers. The centers have different anticoagulation therapy approaches, with more frequent use at HSC relative to $\mathrm{BCCH}$.

SVP was defined as cardiac anatomy that precluded a biventricular repair, usually because 1 ventricle was severely underdeveloped. Exclusion criteria included congenital infection, congenital central nervous system anomaly, and genetic malformation syndrome. Approval for the cohort studies from each of the research ethics boards and parental written consents for all included neonates were obtained.

\section{Clinical Data and Anticoagulation and Antiplatelet Therapy}

For all included neonates, relevant perinatal, clinical, and surgical data were collected by chart review. Anticoagulation therapy was defined as heparin and/or low-molecular-weight heparin (LMWH) started between the pre- and postoperative brain MRI, either before surgery or after surgery when the risk of bleeding had diminished (Figure 1); neonates receiving anticoagulation before the preoperative MRI were excluded. At HSC, anticoagulation therapy is considered routine in neonates with congenital heart disease in case of an ischemic stroke, thrombus at any location, and Blalock-Taussig shunt. Therapy is initiated with unfractionated heparin (maintenance dosage, $28 \mathrm{U} / \mathrm{kg} / \mathrm{h}$ ), titrating to a heparin antifactor Xa level 0.35 to $0.75 \mathrm{U} / \mathrm{mL}$. When levels are adequate, therapy is switched to LMWH at an initial dosage of $1.75 \mathrm{mg} / \mathrm{kg}$ every 12 hours, titrating to a LMWH antifactor $\mathrm{Xa}$ level 0.5 to $1 \mathrm{U} / \mathrm{mL}$. At $\mathrm{BCCH}$, anticoagulation 


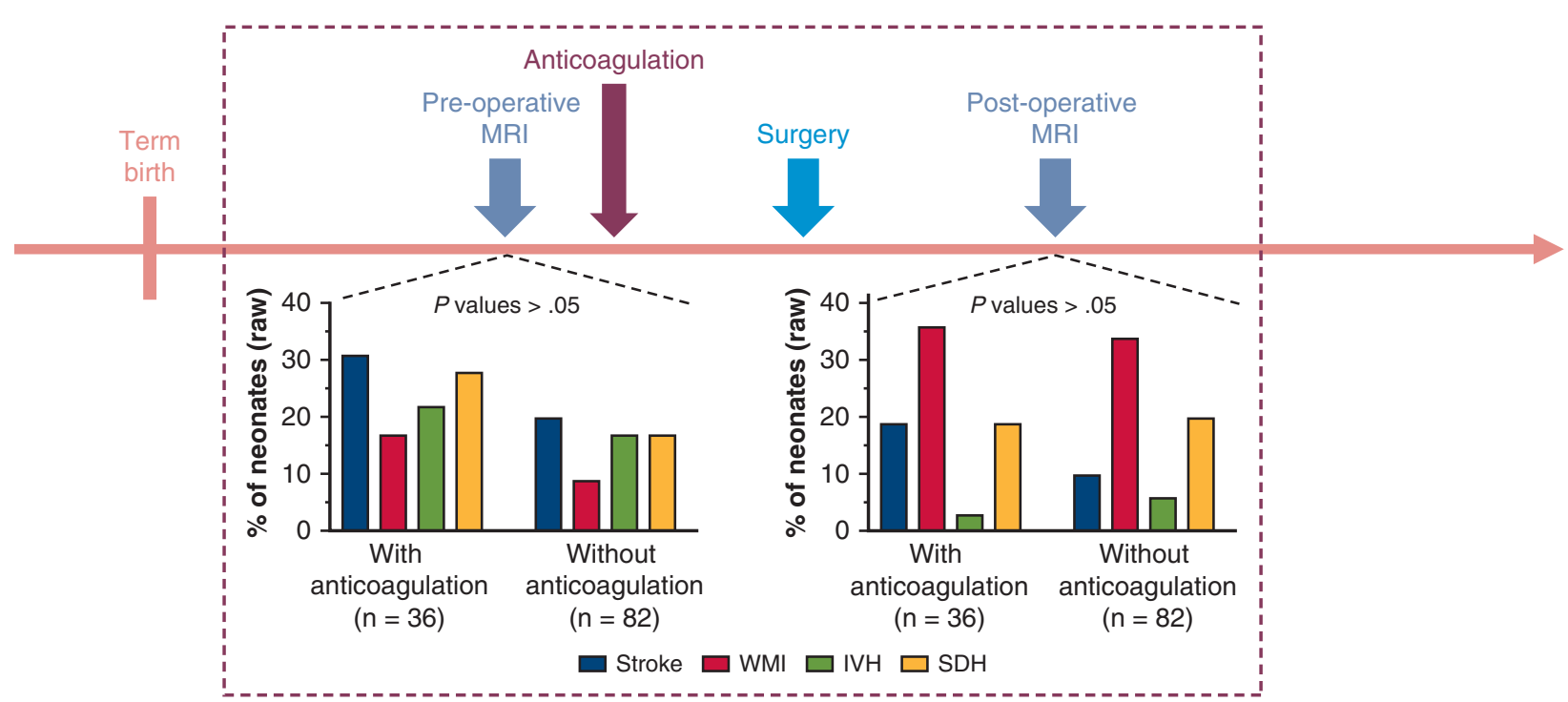

FIGURE 1. Graphs showing the timing of start of anticoagulation therapy in relation to the timing of cardiac surgery and preoperative and postoperative magnetic resonance imaging (MRI) in included neonates with complex congenital heart disease receiving and not receiving anticoagulation. This study addresses anticoagulation initated between the two MRI scans; anticoagulation may have been started before or after surgery. Bar charts represent the raw incidence of preoperative (left) and new postoperative (right) brain injury and subdural hemorrhage for the 2-center cohort of neonates with transposition of the great arteries and single ventricle physiology with and without anticoagulation therapy (ie, heparin or low-molecular-weight heparin). No significant differences in incidence of preoperative and new postoperative brain injury and subdural hemorrhage were identified between neonates with and without anticoagulation for the 2-center cohort, with $P>.05$ for each lesion type. None of the neonates had an intraparenchymal hemorrhage. In a subgroup of neonates, a combination of brain lesions was detected. WMI, White matter injury; $I V H$, intraventricular hemorrhage; $S D H$, subdural hemorrhage.

therapy is started after stroke with a documented embolic source, and cardiac or shunt-related thrombus; anticoagulation therapy is not routinely used for a peripheral thrombus or Blalock-Taussig shunt. Therapy is initiated with unfractionated heparin (loading dose, $75 \mathrm{U} / \mathrm{kg}$; maintenance dosage, $28 \mathrm{U} / \mathrm{kg} / \mathrm{h}$ ), titrating to an anti-factor Xa level 0.5 to $0.75 \mathrm{U} / \mathrm{mL}$. When levels are adequate, therapy is switched to LMWH at an initial dosage of $1 \mathrm{mg} / \mathrm{kg}$ every 12 hours, titrating to an antifactor Xa level 0.5 to $1 \mathrm{U} / \mathrm{mL}$. Details on anticoagulation therapy were collected, including timing of start (ie, before or at surgery) and indication (ie, stroke, thrombus, or Blalock-Taussig shunt).

Antiplatelet therapy (ie, ASA) was regarded separately from anticoagulation. ASA has a different mechanism of action than heparin and LMWH, and is generally associated with a smaller risk of hemorrhagic complications than anticoagulants. At both $\mathrm{HSC}$ and $\mathrm{BCCH}$, antiplatelet therapy is started in neonates requiring a Blalock-Taussig shunt in the setting of SVP, and occasionally when there are concerns about coronary reimplantation after arterial switch surgery in neonates with TGA. Therapy is initiated postoperatively, at a dosage of 5 to $10 \mathrm{mg} / \mathrm{kg} / \mathrm{d}$ orally, when hemostasis from surgical bleeding is achieved and the neonate is tolerating oral nutrition.

\section{Brain MRI}

All neonates underwent pre- and postoperative brain MRI during admission. MRIs were performed as soon as the neonate could be safely transported to the scanner. Scans were performed during sleep after feeding without sedation or contrast. At both centers, MRIs were performed on a 1.5 Tesla Avanto MRI system (Siemens Medical Systems, Erlangen, Germany) according to protocols described previously, ${ }^{6,16}$ consistent throughout the study period, including $\mathrm{T}_{1^{-}}, \mathrm{T}_{2^{-}}$, and diffusion-weighted sequences that are comparable between centers (see Appendix E1). The diffusion imaging data were postprocessed to generate average diffusivity maps.
All MRIs were assessed by the study site neuroradiologist and authors SPM and LML confirmed consistency in diagnosis across centers by consensus. The reviewers were unaware of anticoagulation status. MRIs were scored for presence of acquired brain injury, including ischemic stroke, white matter injury, intraparenchymal hemorrhage, intraventricular hemorrhage, and subdural hemorrhage, as described previously. ${ }^{17}$ Ischemic stroke and white matter injury were regarded as parenchymal injury. The presence of clinically significant hemorrhagic injury, that is, intraparenchymal and intraventricular hemorrhage, and the presence of subdural hemorrhage were assessed from $\mathrm{T}_{1^{-}}$and $\mathrm{T}_{2}$-weighted images because susceptibility-weighted imaging was not consistently available. Intraparenchymal hemorrhage referred to isolated hemorrhage in the brain parenchyma, not related to stroke.

For the preoperative MRIs, presence of brain injury was recorded. For the postoperative MRIs, presence of newly acquired brain injury not evident on the preoperative MRI was recorded.

\section{Statistical Analysis}

Data analyses were performed using IBM SPSS Statistics version 24 (IBM-SPSS Inc, Armonk, NY).

Neonates from the 2 centers were first combined and subsequently divided into 2 groups based on whether or not they received anticoagulation therapy. Categorical variables were compared using the Fisher exact test. Continuous variables were compared using the Mann-Whitney $U$ test. As we had one primary hypothesis, a $P$ value $<.05$ was considered significant.

To address our primary hypothesis, presence of new postoperative brain injury (ischemic stroke, white matter injury, intraparenchymal hemorrhage, or intraventricular hemorrhage) and subdural hemorrhage was compared in the 2-center cohort between neonates with and without anticoagulation. Differences in preoperative brain injury and in perinatal, clinical, and surgical parameters across the 2 groups were explored. To examine whether the anticoagulation association was modified by cardiac 
lesion type or indication, neonates were divided based on cardiac lesion type (ie, TGA or SVP) and presence of indication for anticoagulation (preoperative stroke, preoperative peripheral/intracardiac thrombus, or Blalock-Taussig shunt). Presence of new postoperative brain injury was then compared between neonates with and without anticoagulation. The incidence of new brain injury in neonates receiving anticoagulation with additional antiplatelet therapy relative to neonates receiving only anticoagulation and in neonates admitted to the 2 participating centers separately were described.

\section{RESULTS}

\section{Patients}

A total of 118 neonates enrolled in the 2-center prospective cohort study were included in this secondary analysis: 83 neonates with TGA $(70 \%)$ and 35 neonates with SVP $(30 \%)$, and 67 neonates admitted to HSC (57\%) and 51 neonates admitted to $\mathrm{BCCH}(43 \%)$. The proportions of neonates exposed to anticoagulation therapy and cardiac lesion type differed significantly between the 2 centers, with 31 out of 67 neonates at HSC (46\%) compared with 5 out of 51 neonates at $\mathrm{BCCH}(10 \%)$ receiving anticoagulation therapy $(P<.001)$, and with 28 out of 67 neonates at HSC ( $42 \%)$ compared with 7 out of 51 neonates at BCCH $(14 \%)$ with SVP $(P=.001)$. No other differences in patient characteristics were apparent across centers.

\section{Anticoagulation and Antiplatelet Therapy}

Thirty-six of 118 neonates $(29 \%)$ in the 2-center cohort received anticoagulation therapy: $11(30 \%)$ for preoperative ischemic stroke, $20(56 \%)$ for preoperative peripheral or intracardiac thrombus, and $5(14 \%)$ for BlalockTaussig shunt prophylaxis (Table 1). Neonates receiving anticoagulation did not differ meaningfully from those not receiving anticoagulation (Table 2$)$.

Twenty-four neonates $(20 \% ; 12$ at $\mathrm{HSC}$ and 12 at $\mathrm{BCCH})$ received antiplatelet therapy, of whom $9(38 \%)$ with TGA for concerns about coronary reimplantation, and 15

TABLE 1. Details on anticoagulation therapy (ie, heparin or lowmolecular-weight heparin) in the 36 out of the 118 included neonates $(29 \%)$ with complex congenital heart disease receiving anticoagulation, by cardiac lesion type

\begin{tabular}{lcc}
\hline \multicolumn{1}{c}{ Details } & $\begin{array}{c}\text { Transposition } \\
\text { of the great } \\
\text { arteries }(\mathbf{n}=\mathbf{8 3})\end{array}$ & $\begin{array}{c}\text { Single ventricle } \\
\text { physiology } \\
(\mathbf{n}=\mathbf{3 5})\end{array}$ \\
\hline Anticoagulation & 20 & 16 \\
Center & & \\
$\quad \begin{array}{l}\text { The Hospital for Sick Children } \\
\text { The British Columbia } \\
\quad \text { Children's Hospital }\end{array}$ & 15 & 16 \\
Primary indication \\
$\begin{array}{l}\text { Ischemic stroke } \\
\text { Peripheral/intracardiac } \\
\text { thrombus }\end{array}$ & 5 & 0 \\
Blalock-Taussig shunt \\
$\quad$ prophylaxis
\end{tabular}

TABLE 2. Clinical and imaging parameters for the included neonates with complex congenital heart disease $(n=118)$, separated by neonates with and without anticoagulation therapy (ie, heparin or lowmolecular-weight heparin)

\begin{tabular}{|c|c|c|}
\hline \multirow[b]{2}{*}{ Parameter } & \multicolumn{2}{|c|}{ Anticoagulation therapy } \\
\hline & $\overline{\text { Yes }(n=36)}$ & No $(n=82)$ \\
\hline Antenatal diagnosis (n) & $18(50)$ & $52(63)$ \\
\hline Caesarean delivery (n) & $4(11)$ & $29(35)$ \\
\hline Gestational age (wk) & 38.9 (1.4) & $39.1(1.2)$ \\
\hline Birth weight (kg) & $3.4(0.6)$ & $3.4(0.5)$ \\
\hline Head circumference $(\mathrm{cm})$ & $34.5(1.9)$ & $34.3(1.5)$ \\
\hline Male (n) & $26(72)$ & $53(65)$ \\
\hline Apgar score at $5 \mathrm{~min}$ & $10(1)$ & $9(1)$ \\
\hline Illness severity & $19.5(5.0)$ & $16.1(11.7)$ \\
\hline \multicolumn{3}{|l|}{ Cardiac lesion type } \\
\hline TGA & $20(56)$ & $63(77)$ \\
\hline SVP & $16(44)$ & $19(23)$ \\
\hline Balloon atrial septostomy & $19(53)$ & $50(61)$ \\
\hline Day of life at surgery (d) & $11(13)$ & $12(13)$ \\
\hline Bypass time (min) & $220(53)$ & $163(44)$ \\
\hline Antiplatelet therapy* & $5(14)$ & $20(24)$ \\
\hline ECMO & $7(19)$ & $8(10)$ \\
\hline \multicolumn{3}{|l|}{ Preoperative MRI } \\
\hline Day of life (d) & $5(2)$ & $6(6)$ \\
\hline PMA (wk) & $39.5(1.4)$ & $39.9(1.4)$ \\
\hline \multicolumn{3}{|l|}{ Postoperative MRI } \\
\hline Day of life (d) & $29(19)$ & $22(11)$ \\
\hline PMA (wk) & $43.0(2.8)$ & $42.9(2.2)$ \\
\hline
\end{tabular}

Values are presented as mean \pm standard deviation or $\mathrm{n}(\%)$. Parameters of neonates receiving anticoagulation did not differ meaningfully from those of neonates not receiving anticoagulation. TGA, Transposition of the great arteries; SVP, single ventricle physiology; $E C M O$, extracorporeal membrane oxygenation; $M R I$, magnetic resonance imaging; $P M A$, postmenstrual age. *Acetylsalicylic acid.

$(62 \%)$ with SVP as Blalock-Taussig shunt prophylaxis. Five of these neonates $(20 \%)$ received antiplatelet in addition to anticoagulation therapy, started for preoperative stroke $(\mathrm{n}=2)$ or thrombus $(\mathrm{n}=3)$.

\section{Relation With Anticoagulation Therapy}

A high incidence of preoperative brain injury and of new postoperative brain injury, particularly parenchymal injury, and subdural hemorrhage was found in this cohort (Figure 1). No intraparenchymal hemorrhage was seen in this cohort. No significant differences in incidence of new postoperative brain injury were identified between neonates with and without anticoagulation in the 2-center cohort of neonates with TGA and SVP.

\section{Relation With Anticoagulation Therapy by Cardiac Lesions Type}

The presence of new postoperative brain injury for neonates with and without anticoagulation divided by cardiac 
TABLE 3. Raw incidences of new postoperative brain injury for neonates with complex congenital heart disease with and without anticoagulation therapy (ie, heparin or low-molecular-weight heparin), stratified by cardiac lesion type

\begin{tabular}{|c|c|c|c|c|}
\hline \multirow[b]{3}{*}{ New Postoperative Injury } & \multicolumn{4}{|c|}{ Anticoagulation therapy } \\
\hline & \multicolumn{2}{|c|}{ TGA $(n=83)$} & \multicolumn{2}{|c|}{ SVP $(n=35)$} \\
\hline & $\overline{\text { Yes }(n=20 ; 24 \%)}$ & No $(n=63 ; 76 \%)$ & $\overline{Y e s}(n=16 ; 46 \%)$ & No $(n=19 ; 54 \%)$ \\
\hline Parenchymal injury & $7(35)$ & $27(43)$ & $9(56)$ & $4(21)$ \\
\hline Ischemic stroke & $2(10)$ & $7(11)$ & $5(31)$ & $1(5)$ \\
\hline White matter injury & $7(35)$ & $24(38)$ & $6(38)$ & $4(21)$ \\
\hline Intraventricular hemorrhage & $1(5)$ & $4(6)$ & 0 & $1(5)$ \\
\hline Subdural hemorrhage & $4(20)$ & $11(17)$ & $3(19)$ & $5(26)$ \\
\hline
\end{tabular}

Values are presented as $\mathrm{n}(\%)$. Although no differences were identified for the neonates with TGA, significantly more new postoperative parenchymal injury was found in SVP neonates with compared with without anticoagulation. Boldface indicates a significant difference between the percentages, in this case: between the infants with SVP with anticoagulation and infants with SVP without anticoagulation. TGA, Transposition of the great arteries; SVP, single ventricle physiology.

lesion type is shown in Table 3. When stratified by cardiac lesion, no differences in incidence of new postoperative brain injury were found for the neonates with TGA. In neonates with SVP, significantly more new parenchymal injury $(P=.04)$, mainly attributable to ischemic stroke $(P=.06)$, was found in neonates with compared with without anticoagulation; no difference was observed for intraventricular hemorrhage or subdural hemorrhage.

\section{Relation With Anticoagulation Therapy by Indication for Anticoagulation}

The presence of new postoperative brain injury for neonates with and without anticoagulation with preoperative stroke $(\mathrm{n}=27)$, preoperative peripheral/intracardiac thrombus $(\mathrm{n}=36)$ and Blalock-Taussig shunt $(\mathrm{n}=20)$ is shown in Table 4. In neonates who experienced preoperative stroke, more new subdural hemorrhage $(P=.02)$ was found for neonates with versus without anticoagulation. In all neonates with both preoperative and new postoperative stroke $(n=3)$, postoperative strokes occurred in a different location and were never an extension of the pre-existing stroke; these 3 neonates experienced focal stroke in the periventricular white matter preoperatively, whereas 1 experienced focal stroke in the deep grey matter and 2 had multiple small areas in the white matter postoperatively.
No differences in new postoperative brain injury were found for the neonates with preoperative thrombus or BlalockTaussig shunt.

\section{Relation With Anticoagulation and Antiplatelet Therapy}

In 5 neonates receiving both anticoagulation and antiplatelet therapy, new white matter injury was seen in $80 \%$; new white matter injury was seen in $29 \%$ of neonates receiving only anticoagulation. The incidence of subdural hemorrhage was $40 \%$ in neonates with antiplatelet and anticoagulation and $16 \%$ in neonates receiving only anticoagulation.

\section{Relation With Anticoagulation Therapy by Center and Cardiac Lesions Type}

When described by individual center and cardiac lesion type, the presence of new postoperative brain injury for neonates with and without anticoagulation did not show definitive differences (Tables E1 and E2).

\section{DISCUSSION}

Stroke remains a common and clinically significant complication in neonates with complex congenital heart disease. $4,7,8,13,17-19$ Anticoagulation therapy for

TABLE 4. Raw incidences of new postoperative brain injury for neonates with complex congenital heart disease with and without anticoagulation therapy with preoperative stroke, preoperative thrombus, and Blalock-Taussig shunt. A subgroup of neonates had more than one of these conditions

\begin{tabular}{|c|c|c|c|c|c|c|}
\hline \multirow[b]{3}{*}{ New Postoperative Injury } & \multicolumn{6}{|c|}{ Anticoagulation therapy } \\
\hline & \multicolumn{2}{|c|}{ Preoperative stroke $(n=27)$} & \multicolumn{2}{|c|}{ Preoperative thrombus $(n=36)$} & \multicolumn{2}{|c|}{ Blalock-Taussig shunt $(\mathrm{n}=\mathbf{2 0})$} \\
\hline & Yes $(\mathbf{n}=11)$ & No $(n=16)$ & Yes $(n=28)$ & No $(n=8)$ & Yes $(\mathbf{n}=13)$ & No $(n=7)$ \\
\hline Parenchymal injury & $6(55)$ & $5(31)$ & $14(50)$ & $4(50)$ & $7(54)$ & $2(29)$ \\
\hline Ischemic stroke & $2(18)$ & $1(6)$ & $7(25)$ & 0 & $4(31)$ & $1(14)$ \\
\hline White matter injury & $5(45)$ & $5(31)$ & $11(39)$ & $4(50)$ & $4(31)$ & $2(29)$ \\
\hline Intraventricular hemorrhage & 0 & $1(6)$ & $1(4)$ & 0 & 0 & 0 \\
\hline Subdural hemorrhage & $4(36)$ & $\mathbf{0}$ & $11(39)$ & $3(38)$ & $2(15)$ & $1(14)$ \\
\hline
\end{tabular}

Values are presented as n (\%). Although in neonates with a preoperative stroke more new subdural hemorrhage was found for neonates with compared with without anticoagulation, no differences in new postoperative brain injury were found for the neonates with preoperative thrombus or Blalock-Taussig shunt. Boldface indicates a significant difference between the percentages, in this case: between the infants with preoperative stroke with and without anticoagulation. 
preoperatively detected ischemic stroke or cardiovascular risk factors for thromboemboli formation or extension may be used to reduce the risk of brain injury acquired around or after surgery. Anticoagulation and antiplatelet therapy are also used for specific cardiac indications, such as preventing obstruction of Blalock-Taussig shunt or intracardiac baffle and mechanical or bioprosthetic valve dysfunction. Yet, there are important center-based differences in anticoagulation use. In this descriptive observational cohort study, anticoagulation therapy is not associated with a reduced risk of further perioperative brain injury in neonates with complex congenital heart disease, particularly in the subgroup of neonates with TGA. In neonates with SVP, more new postoperative parenchymal injury was observed in neonates with preoperative ischemic stroke and Blalock-Taussig shunt receiving anticoagulation therapy compared with untreated neonates. These findings suggest that anticoagulation therapy, in its current form, does not reduce neurologic morbidity to the extent anticipated in neonates with complex congenital heart disease at highest risk of embolic brain injury. Our findings also underscore the need for rigorous clinical trials to define optimal use of anticoagulation for further brain injury prevention, relative to its specific cardiac indications, in neonates with complex congenital heart disease.

Stroke in congenital heart disease can be caused by an arterial thrombus, a systemic venous or right-sided intracardiac thrombus traveling through a cardiac shunt, or, in SVP, a thromboembolus originating from the systemic ventricle. Cardiac lesions with shunt, SVP and left-sided cardiac abnormality would be expected to have the highest risk of ischemic stroke and stroke recurrence. Anticoagulation therapy theoretically reduces the risk of brain injury by reducing thromboemboli formation and vascular and/or Blalock-Taussig shunt occlusion. Perioperative anticoagulation therapy is therefore commonly used in neonates with congenital heart disease. However, as reflected by our 2 centers, practice regarding anticoagulation varies widely across centers, including use, indication, timing, bolus at initiation of therapy, therapeutic target levels, and duration, in neonates at risk for stroke. The intercenter variability reflects practitioner's preference and the lack of strong evidence of efficacy with a particular protocol. Protocols are generally adapted from recommendations for children and adolescents, and/or guidelines for adults. ${ }^{20-23}$ The latter guidelines are based on limited evidence from small studies and expert opinion, without validation in randomized controlled trials. Furthermore, these studies may not have included neonates with congenital heart disease.

The etiology of ischemic stroke and the hemostatic system in adults differ considerably from those in neonates. In addition, there are important differences in coagulation factors between neonates with congenital heart disease, even between neonates with similar lesion type. ${ }^{24,25}$ Finally, the time and anticoagulant dose needed to reach therapeutic levels differ substantially between neonates and older children, with dosages and levels being based on limited evidence. All these factors play an important role in the effect of anticoagulation therapy. So far, only a few studies have assessed the potential of anticoagulation to prevent stroke recurrence in neonates and children with congenital heart disease and ischemic stroke. ${ }^{7,13}$ In these studies, most to all infants were treated with an anticoagulant or high-dose antiplatelet agent when a recurrent stroke was detected. ${ }^{7,13}$ The incidences of brain injury in our cohort were comparable to those reported previously. ${ }^{4,6-9,13,17,18}$ Taken together, findings suggest that current perioperative anticoagulation practice is not beneficial for reducing new perioperative brain injury in neonates with complex congenital heart disease, stressing the need for rigorous randomized studies to evaluate the effectiveness of perioperative anticoagulation therapy for brain injury protection.

In neonates with TGA, the arterial switch surgery provides a 1-step correction of cardiovascular anatomy and hemodynamics, with elimination of the right-to-left shunt. Any potential right-sided embolus would be preferentially transmitted to the lungs and may not be clinically apparent. The cardiovascular correction and fast recovery contribute to a reduced risk for cerebral emboli. Consistent with our hypothesis, the incidence of new postoperative injury in neonates with TGA was similar with and without anticoagulation. Limiting anticoagulation use in neonates with TGA might reduce the complexity and costs of their care. These findings support the need for studies that evaluate anticoagulation therapy in this specific population.

The timing of anticoagulation in TGA neonates also merits specific attention. Neonates with insufficient intracardiac left-to-right shunting require a balloon atrial septostomy to improve arterial oxygenation. Balloon atrial septostomy is mostly performed before the preoperative MRI, and thus before anticoagulation is regularly considered. Balloon atrial septostomy has variably been identified as a risk factor for thrombus formation and parenchymal injury. ${ }^{4,6,9,17,26,27}$ In addition, catheterization and vascular access have been associated with a high risk of thrombus formation in these neonates. ${ }^{28}$ Randomized trials that address starting anticoagulation prophylactically before balloon atrial septostomy and/or catheterization would be needed to determine whether this approach is more beneficial than secondary prevention after stroke.

Neonates with SVP would theoretically benefit most from anticoagulation given their multistage surgical course with an ongoing prothrombotic state. With SVP, cardiovascular anatomy and hemodynamic parameters remain abnormal postoperatively with persistent right-to-left shunting, need for vascular access and interventions, and 
risk of complications. These factors contribute to hemodynamic parameter changes, stasis of blood, alterations in coagulation factors and inflammation, and an increased risk of thromboemboli formation and brain injury. ${ }^{12,29}$ Neonates with SVP have the highest risk of thrombosis compared with other cardiac lesion types, particularly following surgery and even with low-dose heparin prophylaxis. ${ }^{30}$ Recurrent strokes have also been described after the second or third surgical stage. ${ }^{12,29,31}$ Consistent with previously reported findings, ${ }^{6}$ we did not observe any hemorrhagic transformation of existing parenchymal injury, even with anticoagulation. We observed more subdural hemorrhage in neonates with preoperative stroke receiving anticoagulation and in neonates receiving both antiplatelet and anticoagulation therapy. Generally, these subdural hemorrhages are small, not clinically relevant, and different in etiology than parenchymal injury (ie, local bleeding vs emboli). These observations suggest that anticoagulation is generally safe and supports its use for specific cardiac indications. However, our findings did not support the hypothesized benefit of recurrent stroke prevention in neonates with SVP, observing more new parenchymal injury, particularly stroke, with anticoagulation. The etiology of these newly acquired parenchymal injuries is likely multifactorial, including differences in thrombotic state due to abnormal cardiac anatomy and function, surgical differences, need for blood products, complications (eg, infection), and invasive procedures, and also chance in a relatively small cohort. Therefore, we are cautious not to ascribe these new injuries to anticoagulation therapy but rather highlight the need for more effective brain injury prevention and for randomized trials on which to base anticoagulation therapy decisions in neonates with congenital heart disease. Alternatively, neonates with SVP and preoperative stroke may be at highest risk of recurrent stroke and the current anticoagulation practice is not sufficient in preventing this. One potential explanation could be that the increase in parenchymal injury in anticoagulated SVP neonates reflects increased emboli from a destabilized thrombus, even while anticoagulation therapy ameliorates clot extension at its source. This explanation is supported by the observation that all 7 neonates with a preoperative thrombus developing a new postoperative stroke received anticoagulation therapy. However, heparin is not a thrombolytic agent per se and adult studies suggest that this explanation is unlikely. ${ }^{32}$ Yet, coagulation pathways in neonates are different from those in adults. Best practice may only be determined by considering competing risk factors (ie, cardiac factors vs stroke prevention) and with the development of rigorous evidence-informed approaches to anticoagulation. Our data support the need to overcome barriers to randomized controlled trials to address this critical issue: small sample size, patient heterogeneity, and costs of neuroimaging and neurodevelopmental follow-up.
Several study limitations are acknowledged. Most importantly, we leveraged cross-center differences in anticoagulation protocols for variability in exposure and did not randomize the neonates to anticoagulation therapy. Although this is the largest cohort to our knowledge of neonates with TGA and SVP with rigorous pre- and postoperative MRI, our sample size precluded further division of the cohort across thrombus location (ie, intracardiac, intrashunt, or systemic vasculature), stroke location, presence of aortic or pulmonary obstruction, or Blalock-Taussig shunt prophylaxis (ie, antiplatelet or anticoagulant). Because the incidence of new postoperative brain injury and patient characteristics did not differ between centers, and none of the BCCH neonates with SVP received anticoagulation, these factors should not have meaningfully influenced our findings. Our sample size precluded addressing differences in surgical techniques and intensive care management over the study period. Based on the available data and retrospective study design, we could not assess individual neonates' hemostatic state, antifactor Xa levels, and LMWH dosing regimens, time in therapeutic target range, blood product requirement, risk of systemic bleeds from anticoagulation therapy, or the relation between anticoagulation and neurodevelopmental outcome. In neonates with congenital heart disease, stroke and especially white matter injury are associated with negative neurodevelopment outcomes, highlighting the importance of preventing these injuries. ${ }^{8,13,33}$ To date, there are no studies providing class- 1 evidence for anticoagulation agent use in neonates with congenital heart disease for preventing perioperative brain injury. Findings from our descriptive observational cohort are intended to inform future trials to determine the optimal use of anticoagulation and of antiplatelet therapy for brain injury prevention in neonates with congenital heart disease given existing practice variability.

\section{CONCLUSIONS}

This descriptive observational study on the association of perioperative anticoagulation and perioperative brain injury in neonates with complex congenital heart disease identifies the critical need for rigorous randomized clinical trials to determine the safety and appropriate indication of anticoagulation therapy in this population. In addition, studies addressing the hemostatic system of neonates with congenital heart disease, and risk factors and biomarkers for a prothrombotic state, are needed. Thrombosis risk stratification based on these factors and cardiac lesion type may allow for more effective approaches to anticoagulation therapy. In the interim, careful consideration of the need for anticoagulation therapy for further perioperative brain injury prevention, relative to specific cardiac indications, in individual neonates with complex congenital heart disease is advised. 


\section{Conflict of Interest Statement}

Dr Synnes received a modest speaker fee at the 52nd Annual Conference of the Japanese Society of Pediatric Cardiology and Cardiac Surgery, Tokyo, Japan, July 6-8, 2016. All other authors have nothing to disclose with regard to commercial support.

The authors thank Claire Watt, Jessie Mei Lim, Amandeep Saini, and Dr Davide Marini for their contributions to performing the brain magnetic resonance imaging examinations, and Janet Rigney for her help with data collection. The authors also thank Dr Mahendranath Moharir for sharing his expertise on the topic and critical reading of the manuscript.

\section{References}

1. Ganesan V, Prengler M, McShane MA, Wade AM, Kirkham FJ. Investigation of risk factors in children with arterial ischemic stroke. Ann Neurol. 2003;53: 167-73.

2. Miller SP, McQuillen PS, Hamrick S, Xu D, Glidden DV, Charlton N, et al. Abnormal brain development in newborns with congenital heart disease. $N$ Engl J Med. 2007;357:1928-38.

3. Licht DJ, Shera DM, Clancy RR, Wernovsky G, Montenegro LM, Nicolson SC, et al. Brain maturation is delayed in infants with complex congenital heart defects. J Thorac Cardiovasc Surg. 2009;137:529-36.

4. Beca J, Gunn J, Coleman L, Hope A, Whelan LC, Gentles T, et al. Preoperative brain injury in newborn infants with transposition of the great arteries occurs at rates similar to other complex congenital heart disease and is not related to balloon atrial septostomy. J Am Coll Cardiol. 2009; 53:1807-11.

5. Limperopoulos C, Tworetzky W, McElhinney DB, Newburger JW, Brown DW, Robertson RL Jr, et al. Brain volume and metabolism in fetuses with congenital heart disease: evaluation with quantitative magnetic resonance imaging and spectroscopy. Circulation. 2010;121:26-33.

6. Block AJ, McQuillen PS, Chau V, Glass H, Poskitt KJ, Barkovich AJ, et al. Clinically silent preoperative brain injuries do not worsen with surgery in neonates with congenital heart disease. J Thorac Cardiovasc Surg. 2010;140:550-7.

7. Rodan L, McCrindle BW, Manlhiot C, MacGregor DL, Askalan R, Moharir M, et al. Stroke recurrence in children with congenital heart disease. Ann Neurol. 2012;72:103-11.

8. Beca J, Gunn JK, Coleman L, Hope A, Reed PW, Hunt RW, et al. New white matter brain injury after infant heart surgery is associated with diagnostic group and the use of circulatory arrest. Circulation. 2013;127:971-9.

9. Dimitropoulos A, McQuillen PS, Sethi V, Moosa A, Chau V, Xu D, et al. Brain injury and development in newborns with critical congenital heart disease. Neurology. 2013;81:241-8.

10. Sun L, Macgowan CK, Sled JG, Yoo SJ, Manlhiot C, Porayette P, et al. Reduced fetal cerebral oxygen consumption is associated with smaller brain size in fetuses with congenital heart disease. Circulation. 2015;131:1313-23.

11. Peyvandi S, De Santiago V, Chakkarapani E, Chau V, Campbell A, Poskitt KJ, et al. Association of prenatal diagnosis of critical congenital heart disease with postnatal brain development and the risk of brain injury. JAMA Pediatr. 2016; 170:e154450

12. Peyvandi S, Kim H, Lau J, Barkovich AJ, Campbell A, Miller S, et al. The association between cardiac physiology, acquired brain injury, and postnatal brain growth in critical congenital heart disease. J Thorac Cardiovasc Surg. 2018; 155:291-300

13. Hoffman JL, Mack GK, Minich LL, Benedict SL, Heywood M, Stoddard GJ, et al. Failure to impact prevalence of arterial ischemic stroke in pediatric cardiac patients over three decades. Congenit Heart Dis. 2011;6:211-8. ch.

14. Kirton A, Armstrong-Wells J, Chang T, Deveber G, Rivkin MJ, Hernandez M, et al. Symptomatic neonatal arterial ischemic stroke: the International Pediatric Stroke Study. Pediatrics. 2011;128:e1402-10.

15. Fullerton HJ, Wu YW, Sidney S, Johnston SC. Risk of recurrent childhood arterial ischemic stroke in a population-based cohort: the importance of cerebrovascular imaging. Pediatrics. 2007;119:495-501.
16. Birca A, Vakorin VA, Porayette P, Madathil S, Chau V, Seed M, et al. Interplay of brain structure and function in neonatal congenital heart disease. Ann Clin Trans Neurol. 2016;3:708-22.

17. McQuillen PS, Hamrick SE, Perez MJ, Barkovich AJ, Glidden DV, Karl TR, et al Balloon atrial septostomy is associated with preoperative stroke in neonates with transposition of the great arteries. Circulation. 2006;113:280-5.

18. McQuillen PS, Barkovich AJ, Hamrick SE, Perez M, Ward P, Glidden DV, et al Temporal and anatomic risk profile of brain injury with neonatal repair of congenital heart defects. Stroke. 2007;38:736-41.

19. Claessens NHP, Algra SO, Jansen NJG, Groenendaal F, de Wit E, Wilbrink AA et al. Clinical and neuroimaging characteristics of cerebral sinovenous thrombosis in neonates undergoing cardiac surgery. $J$ Thorac Cardiovasc Surg. 2018;155:1150-8.

20. Pediatric Stroke Working Group. Stroke in Childhood: Clinical Guidelines for Diagnosis, Management, and Rehabilitation. London: Royal College of Physicians; 2004.

21. Roach ES, Golomb MR, Adams R, Biller J, Daniels S, Deveber G, et al; Amer ican Heart Association Stroke Council; Council on Cardiovascular Disease in the Young. Management of stroke in infants and children: a scientific statement from a Special Writing Group of the American Heart Association Stroke Council and the Council on Cardiovascular Disease in the Young. Stroke. 2008;39:2644-91.

22. Monagle P, Chan AKC, Goldenberg NA, Ichord RN, Journeycake JM, NowakGöttl U, et al. Antithrombotic therapy in neonates and children: antithrombotic therapy and prevention of thrombosis, 9th ed: American College of Chest Physicians evidence-based clinical practice guidelines. Chest. 2012;141: e737S-801S.

23. Giglia TM, Massicotte MP, Tweddell JS, Barst RJ, Bauman M, Erickson CC, et al; American Heart Association Congenital Heart Defects Committee of the Council on Cardiovascular Disease in the Young, Council on Cardiovascular and Stroke Nursing, Council on Epidemiology and Prevention, and Stroke Council. Prevention and treatment of thrombosis in pediatric and congenital heart disease: a scientific statement from the American Heart Association. Circulation. 2013;128:2622-703.

24. Cheung EWY, Chay GW, Ma ESK, Cheung Y. Systemic oxygen saturation and coagulation factor abnormalities before and after the Fontan procedure. Am J Cardiol. 2005;96:1571-5.

25. Hakacova N, Laluhova-Striezencova Z, Zahorec M. Disturbances of coagulation in neonates with functionally univentricular physiology prior to the first stage of surgical reconstruction. Cardiol Young. 2008;18:397-401.

26. Doshi H, Venugopal P, MacArthur K. Does a balloon atrial septostomy performed before arterial switch surgery increase adverse neurological outcomes? Interact Cardiovasc Thorac Surg. 2012;15:141-3.

27. Polito A, Ricci Z, Fragasso T, Cogo PE. Balloon atrial septostomy and preoperative brain injury in neonates with transposition of the great arteries: a systematic review and a meta-analysis. Cardiol Young. 2012;22:1-7.

28. Mathews RA, Park SC, Neches WH, Fricker FJ, Lenox CC, Zuberbuhler JR. Iliac venous thrombosis in infants and children after cardiac catheterization. Cathet Cardiovasc Diagn. 1979;5:67-74.

29. Domi T, Edgell DS, McCrindle BW, Williams WG, Chan AK, MacGregor DL, et al. Frequency, predictors, and neurologic outcomes of vaso-occlusive strokes associated with cardiac surgery in children. Pediatrics. 2008; 122:1292-8.

30. Emani S, Zurakowski D, Baird CW, Pigula FA, Trenor C, Emani SM. Hypercoagulability markers predict thrombosis in single ventricle neonates undergoing cardiac surgery. Ann Thorac Surg. 2013;96:651-6.

31. Anderson PA, Sleeper LA, Mahony L, Colan SD, Atz AM, Breitbart RE, et al Contemporary outcomes after the Fontan procedure: a Pediatric Heart Network multicenter study. J Am Coll Cardiol. 2008;52:85-98.

32. Djulbegovic M, Lee AI. An update on the "novel" and direct oral anticoagulants and long-term anticoagulant therapy. Clin Chest Med. 2018;39:583-93.

33. Reich B, Heye K, Tuura R, Beck I, Wetterling K, Hahn A, et al. Neurodevelopmental outcome and health-related quality of life in children with single-ventricle heart disease before Fontan procedure. Semin Thorac Cardiovasc Surg. 2017;29: 504-13.

Key Words: stroke, white matter injury, transposition of the great arteries, single ventricle physiology, heparin, anticoagulation 


\section{APPENDIX E1}

At The Hospital for Sick Children, imaging included 3dimensional sagittal volumetric $\mathrm{T}_{1}$-weighted images $(1920 / 3.2 / 200 \mathrm{~mm} / 0.8 \mathrm{~mm})$, axial turbo spin echo $\mathrm{T}_{2^{-}}$ weighted images $(9970 / 210 / 113 \times 140 \mathrm{~mm} / 4 \mathrm{~mm})$, and diffusion tensor imaging $(7300 / 97 / 160 \mathrm{~mm} / 2 \mathrm{~mm})$ with spatial resolution of $2 \mathrm{~mm}$. At The British Columbia Children's Hospital imaging included 3-dimensional coronal volumetric $\mathrm{T}_{1}$-weighted images $(36 / 9.2 / 200 \mathrm{~mm} / 1 \mathrm{~mm})$, axial fast spin echo $\mathrm{T}_{2}$-weighted images (4610/107/ $160 \mathrm{~mm} / 4 \mathrm{~mm}$ ), and diffusion tensor imaging (4900/104/ $160 \mathrm{~mm} / 3 \mathrm{~mm}$ ) with spatial resolution of $1.3 \mathrm{~mm}$. 
TABLE E1. Raw incidences of new postoperative brain injury for neonates with complex congenital heart disease admitted to The Hospital for Sick Children with and without anticoagulation therapy (ie, heparin or low-molecular-weight heparin), stratified by cardiac lesion type

\begin{tabular}{lcccc}
\hline & \multicolumn{3}{c}{ Anticoagulation therapy } \\
\cline { 2 - 5 } New Postoperative Injury & \multicolumn{2}{c}{ TGA $(\mathbf{n}=\mathbf{3 9})$} & \multicolumn{2}{c}{ SVP $(\mathbf{n}=\mathbf{2 8})$} \\
\hline Parenchymal injury & $\mathbf{6}(\mathbf{4 0})$ & $\mathbf{1 9}(\mathbf{7 9})$ & $\mathbf{\text { Yes }}(\mathbf{n}=\mathbf{1 6} ; \mathbf{5 7} \%)$ & $\mathbf{N o}(\mathbf{n}=\mathbf{1 2} ; \mathbf{4 3} \%)$ \\
\hline Ischemic stroke & $2(13)$ & $3(13)$ & $5(36)$ & $\mathbf{2}(\mathbf{1 7})$ \\
White matter injury & $\mathbf{6}(\mathbf{4 0})$ & $\mathbf{1 8}(\mathbf{7 5})$ & $6(38)$ & $2(8)$ \\
Intraventricular hemorrhage & $1(7)$ & $0(0)$ & $0(0)$ & $0(0)$ \\
Subdural hemorrhage & $4(27)$ & $4(17)$ & $3(19)$ & $1(8)$ \\
\hline
\end{tabular}

Parameters are depicted as $\mathrm{n}(\%)$. Although slightly less parenchymal injury, mostly attributable to white matter injury, was observed in TGA neonates with relative to without anticoagulation and slightly more parenchymal injury was observed in SVP neonates with relative to without anticoagulation, no definitive differences were observed between neonates with and without anticoagulation. Boldface indicates clear (but nonsignificant) difference between the percentages, in this case: between infants with and without anticoagulation. TGA, Transposition of the great arteries; SVP, single ventricle physiology.

TABLE E2. Raw incidences of new postoperative brain injury for neonates with complex congenital heart disease admitted to The British Columbia Children's Hospital with and without anticoagulation therapy (ie, heparin or low-molecular-weight heparin), stratified by cardiac lesion type

\begin{tabular}{|c|c|c|c|c|}
\hline \multirow[b]{3}{*}{ New Postoperative Injury } & \multicolumn{4}{|c|}{ Anticoagulation therapy } \\
\hline & \multicolumn{2}{|c|}{ TGA $(n=44)$} & \multicolumn{2}{|c|}{$\begin{array}{l}\text { SVP }(n=7) \\
\end{array}$} \\
\hline & Yes $(n=5 ; 11 \%)$ & No $(n=39 ; 89 \%)$ & Yes $(n=0 ; 0 \%)$ & No $(n=7 ; 100 \%)$ \\
\hline Parenchymal injury & $1(20)$ & $8(21)$ & NA & $2(29)$ \\
\hline Ischemic stroke & $0(0)$ & $4(10)$ & & $0(0)$ \\
\hline White matter injury & $1(20)$ & $6(15)$ & & $2(29)$ \\
\hline Intraventricular hemorrhage & $0(0)$ & $4(10)$ & & $1(14)$ \\
\hline Subdural hemorrhage & $0(0)$ & $7(18)$ & & $4(57)$ \\
\hline
\end{tabular}

Parameters are depicted as $\mathrm{n}(\%)$. No definitive differences in brain injury and subdural hemorrhage were observed between neonates with and without anticoagulation, both for TGA and SVP neonates. TGA, Transposition of the great arteries; SVP, single ventricle physiology; $N A$, not applicable. 